\title{
CORRESPONDENCE
}

Wasting blood

J M Cundy, FFARCS, and V Jeevananthan, FFARCS

Noradrenaline: a circulating inhibitor of sodium transport

D N Baron, FRCPATH, and others; A Riozzi, BSC, and others; J A Millar, MRCP, and P M Bramley, BSC . . . . 151

Lymphocytes are rhythmic: is this important?

A G Fennerty, MRCP, and others; J S Dixon, AHD, and o

Certifying death in infancy

M R Alderson, FFCM, and others.

Coronary artery bypass grafting

R B Pridie, FRCR; Elizabeth M Russell, FFCM; R R West, PHD, and Jean M Weddell, FFCM; B S Smith, FRCP; D H Spodick, MD 153

Hospital building in the NHS

F J Gibbins, FRCP

Algorithm for modified alkaline diuresis in salicylate poisoning

I A Vale, MD, and others; I J Gordon, MRCP 155

Clinical algorithms: generalised pruritus

A Munro, MD; R H Champion, FRCP...... 155

Value of follow up in testicular cancer

G Read, FRCR, and others........... 155

Trimethoprim resistance in Gram

negative urinary pathogens

Rosalind Maskell, DM..............

Calcium supplementation and postmenopausal bone loss

W H Taylor, FRCP; Lisbeth Nilas, MD,

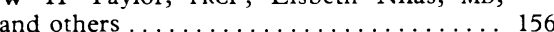

Instructions for inhalers

A L Pozniak, MRCP, and N MCI Johnson, MD 157

Acute diarrhoea in children

W A $M$ Cutting, FRCPED, and Fiona $M$

Hardy, MRCGP............... 157

Can we have safer cigarettes?

F Ledwith, PHD, and Matti Rimpela, MD . . 157

Tobacco tarred gold?

Gabriel Scally, MFCM............... 158

"Tobacco teabags"

A S High, FDS RCSED ............ 158

Serum cortisol concentrations during low

dose dexamethasone suppression test

to screen for Cushing's syndrome

D Mattingly, FRCP, and Christine Tyler,

PHD; L Kennedy, MD, and others........ 1

Plasma theophylline concentrations, six

minute walking distances, and

breathlessness in patients with chronic airflow obstruction

A J Miller, MRCP, and others; W V Evans, MRCP; A C Davidson, MRCP, and C B Cooper, MRCP.

Reliability of cardiotocography in

predicting baby's condition at birth

Mary Pillai, MB; M J Whittle, MRCog;

P Curzen, FRCOG, and others.......... 160
Cardiac arrest after treatment with intravenous domperidone

H A Cameron, MRCP, and others........ 160

Medical journals in the Third World

T Waterston, MRCP.............. 160

Hypoglycaemia in acute

myelomonoblastic leukaemia

I C Macdougall, MB, and B M Frier, FRCPED 161

Is unemployment a cause of parasuicide?

S Platt, PHD, and N Kreitman, MD . . . . . . 161

Brain stem death

M Colebrook, MB

Points Plasmodium falciparum imported from the Punjab (R P Britt and Betty Cowan); NHS thik hai? (M O Lobb); Colposcopy and ablative therapy (R G Wright and $\mathrm{M} \mathrm{J}$ Webb); Tuberculosis in hospital doctors (M S Gatley); Lipoid pneumonia: an occupational hazard of fire eaters (R W Whitehouse); Clinical algorithms: short stature (R T D FitzGerald); Is unemployment a cause of parasuicide? (J A Furness and others); Routine reuse of plastic insulin syringes (C Fletcher); Diarrhoea, dehydration, and drugs ( Mason); Generalised epileptic fits in renal transplant recipients given cyclosporin A ( $\mathrm{P} \mathrm{H}$ Whiting and others); Measuring coagulation ( $G$ Gogstad)............ 162

Because we receive many more letters than we have room to publish we may shorten those that we do publish to allow readers as wide a selection as possible. In particular, when we receive several letters on the same topic we reserve the right to abridge individual letters.

Letters critical of a paper may be sent to the authors of the paper so that their reply may appear in the same issue.

We may also forward letters that we decide not to publish to the authors of the paper on which they comment.

Letters should not exceed 400 words and should be typed double spaced and signed by all authors, who should

include their main degree.

\section{Wasting blood}

SIR,-May we suggest that recent reports of transmission of the acquired immune deficiency syndrome virus by blood transfusion should cause a reappraisal of transfusion practice in the United Kingdom. The transfusion of a single unit of blood can rarely if ever be justified and closer attention needs to be paid to the balance of risks and benefits.

In a study which we undertook of the transfusion practice of UK anaesthetists it was apparent that $10 \mathrm{~g} / \mathrm{dl}$ of haemoglobin was regarded by most anaesthetists as the leve below which preoperative measures to raise the haemoglobin level were indicated. We believe that by adopting $8 \mathrm{~g} / \mathrm{dl}$ as a lower acceptable level for patients undergoing major surgery we could reduce the requirements for blood transfusion considerably, thus minimising the associated risks to patients. ${ }^{1}$ For patients undergoing short operative procedure with little risk of haemorrhage even lower haemoglobin levels could be accepted provided the patient was otherwise fit. ${ }^{2}$

Several papers have recently shown that for most operations blood loss can be reasonably predicted, and the modern anaesthetist should be able to plan intraoperative trans fusion regimens which protect the patient from the dangers of haemorrhage and also avoid unnecessary transfusion. ${ }^{3}$

J M CUNDY

Lewisham Hospital,
London SE13 6LH

1 Pineda AA, Braica GM, Taswell HF. Haemolytic ransfusion reaction, recent experience in a large blood bank. Mayo Clin Proc 1978;53:378.

2 Graves CL, Allan RM. Anaesthesia in the presence of severe anaemia. Rocky Mountain Medical fournal $1970 ; 67: 35$

Stehling LC. Guidelines for ordering blood for elective surgery. Int Anesthesiol Clin 1982;21:45.

\section{Noradrenaline: a circulating inhibitor} of sodium transport

SiR,-Mr A Riozzi and coworkers (20 October, p 1025) describe a noradrenaline mediated, dose dependent reduction of leucocyte sodium efflux rate constant which was due to decrease in ouabain sensitive sodium pump activity. They also report that this effect was blocked by propranolol, suggesting that it was mediated by $\beta$ adrenoceptors. Furthermore, they suggest a possible circulating inhibitory role for catecholamines on codium transport.
Using mixed human leucocytes we showed a stimulatory effect of adrenaline $(9 \mathrm{nmol} / \mathrm{l})$ on both rubidium (equivalent to potassium) influx and sodium efflux and that this was mediated by $\beta_{2}$ adrenoceptors. We were unable to show any such effects using fresh noradrenaline $(10-300 \mathrm{nmol} / 1) .^{2}$ Our findings are compatible with the known effects of adrenaline infusion, which causes hypokalaemia in vivo, without increased urinary potassium loss, presumably by moving potassium into cells ${ }^{34}$; noradrenaline infusion does not affect plasma potassium concentration. ${ }^{5}$

Leucocytes are thought to possess $\beta_{2}$ adrenoceptors but not $\beta_{1}$ adrenoceptors, ${ }^{6}$ and noradrenaline is also known to act principally on $\alpha_{1}, \alpha_{2}$, and $\beta_{1}$ adrenoceptors. ${ }^{7}$ Consequently, it would be surprising to observe any mediated effects of noradrenaline on human leucocytes. Studies using adrenergic challenge in man have supported the contention that the relation between the sodium pump-that is, $\mathrm{Na}^{+}, \mathrm{K}^{+}$-ATPase-and catecholamines is mediated through $\beta_{2}$ adrenoceptors. ${ }^{8}$

The discrepancies between our results and those of Mr Riozzi and others are likely to be caused by differences in the experimental models. They exposed leucocytes, in serum, to noredrenaline for 10 minutes during loading 